\title{
Evaluation of systemic absorption and bronchodilator effect of glycopyrronium bromide delivered by nebulizer or a dry powder inhaler in subjects with chronic obstructive pulmonary disease
}

Brian R. Leaker ${ }^{1 *}$, Dave Singh², Grant C. Nicholson, Blanka Hezelova', Thomas Goodin ${ }^{3}$, Ayca Ozol-Godfrey ${ }^{3}$, Gerald Galluppi ${ }^{3}$ and Peter J. Barnes ${ }^{4}$

\begin{abstract}
Background: Effective bronchodilator therapy depends upon adequate drug deposition in the lung. COPD patients who are unable to administer medications efficiently with conventional inhalers may benefit from the use of a nebulizer device. The aim of this study was to evaluate the systemic bioavailability and bronchodilator response of glycopyrronium bromide (GLY) administered by a novel nebulizer (eFlow ${ }^{\circledast}$ closed system [CS] vibrating membrane nebulizer) or dry powder inhaler (DPI) in subjects with moderate-to-severe chronic obstructive pulmonary disease (COPD).

Methods: In this randomized, open-label, single-dose, five-way crossover study, subjects received a sequence of either $50 \mu \mathrm{g}$ GLY delivered by eFlow CS nebulizer (GLY/eFlow) or $63 \mu \mathrm{g}$ GLY delivered by DPI (GLY/DPI), with and without activated charcoal, followed by intravenous infusion of $50 \mu \mathrm{g} G \mathrm{G}$ with a washout period of 7 days between doses. Endpoints included plasma pharmacokinetics, safety and efficacy.
\end{abstract}

Results: The mean $( \pm \mathrm{SD})$ baseline predicted forced expiratory volume in $1 \mathrm{~s}\left(\mathrm{FEV}_{1}\right)$ of the 30 subjects who completed the study was $51 \pm 15 \%$, with a FEV $1 /$ forced vital capacity ratio of $50 \pm 11 \%$. Without charcoal, the absolute systemic bioavailability of GLY/eFlow and GLY/DPI were approximately 15 and 22\%, respectively. Changes from baseline in FEV at 60 min post-dose, without administration of charcoal, were $0.180 \mathrm{~L}$ and $0.220 \mathrm{~L}$ for GLY/eFlow and GLY/DPI, respectively; FEV 1 improvements were similar when charcoal was administered $(0.220 \mathrm{~L}$ for both GLY/eFlow and GLY/DPI). There were no significant differences in spirometry between the two devices. Fewer subjects administered GLY/eFlow reported adverse events $(n=15)$ than GLY/DPI $(n=18)$.

Conclusions: After single doses, GLY/DPI delivered numerically higher peak and steady state levels of drug than did GLY/eFlow. Nebulized GLY produced similar bronchodilation but lower systemic levels of drug than GLY/DPI. Slightly higher number of subjects reported adverse events with GLY/DPI than with GLY/eFlow. Nebulized GLY may offer an effective alternative to patients with COPD not adequately treated with other devices.

Trial registration: NCT02512302 (ClinicalTrials.gov). Registered 28 May 2015.

Keywords: COPD, Nebulizer, Glycopyrronium bromide, Bioavailability

\footnotetext{
* Correspondence: brian.leaker@qasmc.com

${ }^{1}$ Respiratory Clinical Trials Ltd, 20 Queen Anne Street, London W1G 8HU, UK

Full list of author information is available at the end of the article
}

(c) The Author(s). 2019 Open Access This article is distributed under the terms of the Creative Commons Attribution 4.0 International License (http://creativecommons.org/licenses/by/4.0/), which permits unrestricted use, distribution, and

reproduction in any medium, provided you give appropriate credit to the original author(s) and the source, provide a link to the Creative Commons license, and indicate if changes were made. The Creative Commons Public Domain Dedication waiver (http://creativecommons.org/publicdomain/zero/1.0/) applies to the data made available in this article, unless otherwise stated. 


\section{Background}

Chronic obstructive pulmonary disease (COPD) is a prevalent respiratory disease associated with chronic lung inflammation that stems from prolonged exposure to toxic particles, primarily tobacco smoke. The persistent infiltration of inflammatory immune cells leads to parenchymal destruction and to the thickening and narrowing of small airways that result in air trapping and progressive airway obstruction. Although airway obstruction in COPD is largely irreversible, intrinsic cholinergic tone produces further narrowing that is reversible with inhaled bronchodilators. Long-acting bronchodilators, such as long-acting muscarinic antagonists (LAMA), reduce air trapping and improve symptoms in COPD patients [1].

Glycopyrronium bromide (GLY) is a competitive and potent LAMA that has a relative inhibitory effect predominantly on $\mathrm{M}_{3}$ muscarinic acetylcholine receptors. The binding of GLY to these receptors inhibits acetylcholine-mediated bronchoconstriction [2], reducing air trapping, increasing forced expiratory volume in $1 \mathrm{~s}\left(\mathrm{FEV}_{1}\right)$ and reducing symptoms.

A soluble formulation of GLY (SUN-101, formerly known as EP-101) has been developed for nebulized delivery. Nebulizers are an effective way to deliver drugs to COPD patients who may have difficulty using handheld inhalers because of low inspiratory flow rates that may make it difficult to use dry powder inhalers (DPI) efficiently. The eFlow ${ }^{\bullet}$ closed system (CS) device (Fig. 1) is a portable, handheld, high efficiency nebulizer (PARI Pharma GmbH, Starnberg, Germany) [3]. Nebulized GLY delivered via the eFlow CS device (GLY/eFlow; Lonhala $^{\oplus}$ Magnair ${ }^{\oplus}, 25 \mu$ g twice daily [BID]) is approved in the USA for the long-term maintenance treatment of airflow obstruction in patients with COPD [4].

The efficiency of symptom control over time greatly depends on the correct administration technique. However, studies have observed that the majority of COPD

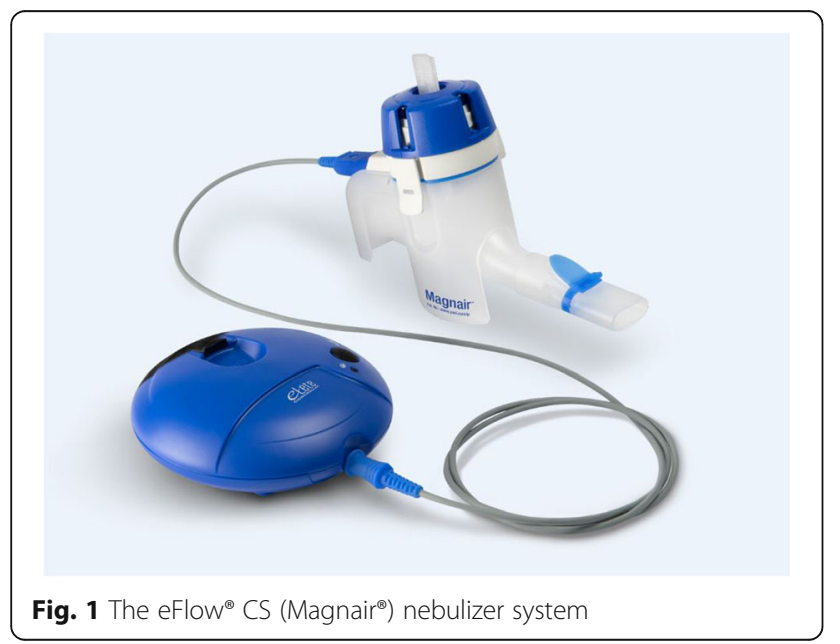

patients commit at least one error when attempting to coordinate inhalation with actuation when using pressurized metered dose inhalers (pMDI) and DPIs [5]. Patient characteristics, such as ability to generate an adequate inspiratory flow, can impact effective drug delivery to the lungs. Nebulizer devices may offer advantages to certain COPD patients who are unable to administer medications efficiently with conventional inhalers. Drug deposition in the airways of nebulized or dry powder bronchodilator formulations can be associated with the particle size generated by the respective devices. The eflow CS nebulizer delivers GLY aerosols with a mean droplet size $(3.7 \mu \mathrm{m})$ that may be suitable for central and peripheral airway deposition [6]. The mean size of GLY particle delivered via the Breezhaler DPI is $3.2 \mu \mathrm{m}$, with mean estimated intrathoracic and extrathoracic drug deposition of 31 and 57\%, respectively [7].

The aim of this study was to evaluate the total systemic exposure and lung bioavailability of GLY/eFlow and GLY/DPI (Seebri ${ }^{\odot}$ Breezhaler ${ }^{\odot}$ ) in subjects with moderate-to-severe COPD. This was achieved using treatment arms with and without activated charcoal to block gastrointestinal drug absorption, to determine the systemic pharmacokinetics (PK) of inhaled GLY versus intravenous GLY and evaluate the effects of both treatments on lung bioavailability and lung function.

\section{Methods}

\section{Study subjects}

Males or females aged 40 to 70 years with a clinical diagnosis of moderate-to-severe COPD were eligible. We referred to the Global Initiative for Chronic Obstructive Lung Disease (GOLD 2014) for diagnosis and severity. Subjects were required to be current or ex-smokers with at least 10 pack-year history. Women of childbearing potential were only eligible after a negative urine pregnancy test and if they agreed to use an acceptable method of birth control throughout the study. Postbronchodilator $\mathrm{FEV}_{1}$ was $30-80 \%$ of predicted normal and $\mathrm{FEV}_{1} /$ forced vital capacity (FVC) ratio of $\leq 0.70$ at the screening visit. Subjects were required to perform reproducible spirometry to ensure accurate readings. Subjects were excluded from the study if they had concomitant clinically significant respiratory disease other than COPD, including asthma, tuberculosis, bronchiectasis or other nonspecific pulmonary disease, or respiratory tract infection within 6 weeks prior to Screening. Prior COPD medications (up to 30 days before screening; patients could use $>1$ prior medication) included fluticasone/salmeterol $(n=11)$, umeclidinium/vilanterol $(n=1)$, budesonide/formoterol $(n=2)$, budesonide/eformoterol $(n=4)$, tiotropium $(n=11)$, salbutamol $(n=11)$, terbutaline $(n=1)$ and aclidinium $(n=1)$. 
Subjects were fully informed of the risks of taking part in the study and were free to withdraw at any point. Written informed consent was obtained from subjects prior to any study procedure taking place. The GOLDEN 7 (SUN101-105) study protocol was approved by East of England - Cambridgeshire and Hertfordshire Research Ethics Committee (reference: 15/EE/0296) prior to patient enrollment and was conducted according to International Council for Harmonization Good Clinical Practice guidelines and the ethical principles outlined in the Declaration of Helsinki. After providing consent for study participation, subjects entered a 3-week screening period to allow for appropriate washout of their usual medication and to determine study eligibility. During the study, the use of inhaled corticosteroids (ICS) and shortacting bronchodilators was permitted.

\section{Study design}

We performed a randomized, open-label, single-dose per dosing period, five-way crossover study in two centers in the United Kingdom. The study aimed to evaluate the PK and absolute bioavailability of GLY delivered via eFlow CS nebulizer relative to delivery via DPI. The study did not seek to directly compare the two GLY formulations and delivery devices in terms of bioequivalence.

Intravenous (IV) administration of $50 \mu \mathrm{g}$ GLY (0.25 $\mathrm{mL}$ from the $200 \mu \mathrm{g} / \mathrm{mL}$ injection vial), which delivers $100 \%$ of the dose, was the normalization standard for PK calculations. The GLY/DPI capsules contained $63 \mu \mathrm{g}$ GLY (approved dose in the United Kingdom), of which $88 \%$ (corresponding to $55.4 \mu \mathrm{g}$ ) is delivered through the device [8]. Therefore, a dose-normalization factor of 0.9 (50/55.4) relative to $50 \mu \mathrm{g}$ GLY IV delivery was applied to GLY/DPI PK calculations [8]. Similar to DPIs, the efficiency of nebulizer devices depends on patient and device factors. In this study, a $50 \mu \mathrm{g}$ dose of GLY administered via the eFlow CS nebulizer was calculated to deliver $63 \%$ of GLY $(31.5 \mu \mathrm{g})$ during administration. A normalization factor of $1.59(50 / 31.5)$ was applied to the GLY/eFlow PK calculations [4].

During the treatment phase of the study, subjects underwent randomization and entered one of ten treatment sequences. Five treatment arms were designed to evaluate the PK profile of GLY administered by different devices (nebulizer or DPI), with or without concomitant oral intake of activated charcoal to prevent gastrointestinal absorption (Table 1). Two $5 \times 5$ Latin Squares balanced for first-order carry-over effects were employed for this crossover study (Additional file 1). The data obtained were also compared to the bioavailability of GLY when administered IV. Single-dose administration was assessed as it is more sensitive than repeated dose or steady-state administration.
Table 1 Treatments included in the study

\begin{tabular}{|c|c|c|}
\hline Treatment & Dose & $\begin{array}{l}\text { Mode of } \\
\text { administration }\end{array}$ \\
\hline GLY via the eFlow CS nebulizer ${ }^{a}$ & $50 \mu \mathrm{g}$ & $\begin{array}{l}\text { Electronic } \\
\text { nebulizer }\end{array}$ \\
\hline $\begin{array}{l}\text { GLY via the eFlow CS nebulizer } \\
\text { with activated charcoal }\end{array}$ & $50 \mu \mathrm{g}$ & $\begin{array}{l}\text { Electronic } \\
\text { nebulizer }\end{array}$ \\
\hline GLY via DPI ${ }^{b}$ & $63 \mu \mathrm{g}$ & DPI \\
\hline GLY via DPI ${ }^{\mathrm{b}}$ with activated charcoal & $63 \mu \mathrm{g}$ & DPI \\
\hline GLY sterile solution ${ }^{c}$ & $50 \mu \mathrm{g}$ & 5-min IV infusion \\
\hline
\end{tabular}

CS closed system, DPI dry powder inhaler, GLY glycopyrronium bromide, IV intravenous

${ }^{\mathrm{a}}$ The dose for nebulized GLY was $50 \mu \mathrm{g}$ per ampule

${ }^{\text {b}}$ The dose for GLY inhalation powder was $63 \mu \mathrm{g}$ per capsule

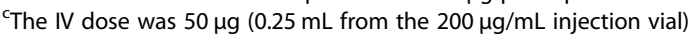

Subjects were required to attend the clinical site on the day of treatment, having fasted from solid food for 8 $\mathrm{h}$ prior to dosing and from fluids for $2 \mathrm{~h}$ prior to dosing. At each visit (Fig. 2), subjects received a single dose of the study medication according to their assigned treatment sequence. The study medication was administered in the morning and subjects remained at the study site for $24 \mathrm{~h}$ after dosing, during which PK samples were collected. Blood pressure and heart rate were assessed within $30 \mathrm{~min}$ pre-dose and $1 \mathrm{~h}( \pm 5 \mathrm{~min})$ post-dose. A minimum 7-day washout period was required between visits. Additionally, subjects had a follow-up telephone contact on Day $36( \pm 1$ day) to assess safety. Adverse event $(\mathrm{AE})$ monitoring began once a subject signed the informed consent and continued until the last study visit.

\section{Pharmacokinetic assessments}

The primary endpoints were maximum observed plasma concentration $\left(\mathrm{C}_{\max }\right)$ area under the plasma concentration time curve from 0 to $24 \mathrm{~h}$ and to infinity post-dose $\left(\mathrm{AUC}_{0-24}\right.$ and $\left.\mathrm{AUC}_{0-\infty}\right)$. Secondary endpoints included clearance $(\mathrm{CL})$, fraction bioavailable $(\mathrm{F}), \mathrm{CL} / \mathrm{F}$, volume of distribution $\left(\mathrm{V}_{\mathrm{z}}\right), \mathrm{V}_{\mathrm{z}} / \mathrm{F}$, time to reach maximum plasma concentration $\left(t_{\max }\right)$, elimination half-life $\left(t_{1 / 2}\right)$, dose normalized $\mathrm{C}_{\max }$, and $\mathrm{AUC}_{0-24}, \mathrm{AUC}_{0-48}$ and $\mathrm{AUC}_{0-\infty}$ (based on actual dose delivered).

PK samples were collected within 15 min prior to dosing, immediately at the end of inhalation $(\sim 5 \mathrm{~min}$ from the start of inhalation), immediately at the end of IV infusion ( $5 \mathrm{~min}$ from the start of IV infusion), and postdose at $0.25-0.5 \mathrm{~h}, 1.5-2.5 \mathrm{~h}, 6-8 \mathrm{~h}, 12 \mathrm{~h}( \pm 15 \mathrm{~min}), 13-$ $16 \mathrm{~h}, 24 \mathrm{~h}( \pm 15 \mathrm{~min})$ and $48 \mathrm{~h}( \pm 15 \mathrm{~min})$. Blood samples were collected within the prespecified time windows rather than at strict sampling times. A validated bioanalytical liquid chromatography tandem mass spectrometry method with a lower limit of quantification of $4 \mathrm{pg} / \mathrm{mL}$ was used to determine GLY concentrations. 


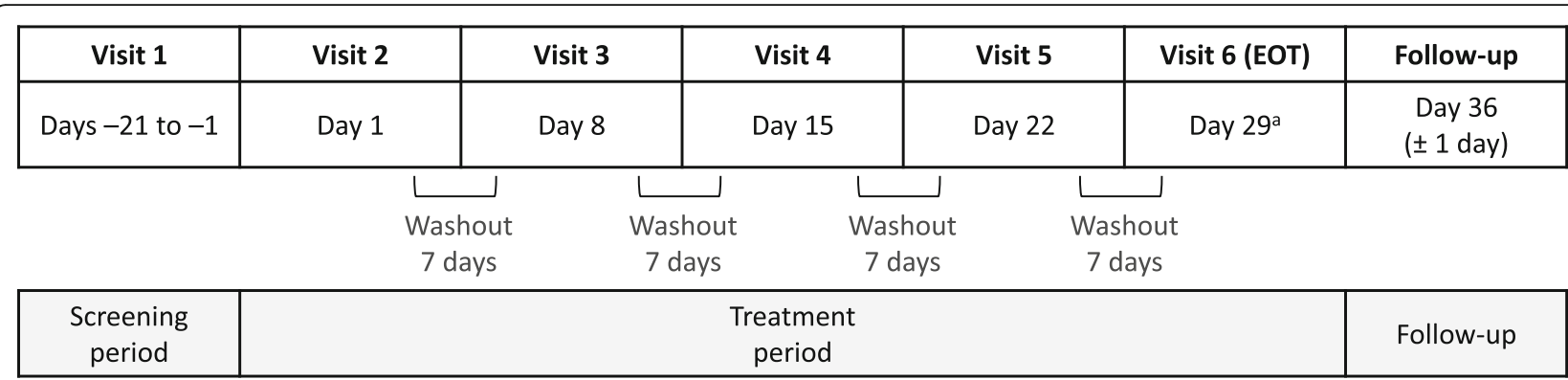

Fig. 2 GOLDEN 7 study schematic. Washout of more than 7 days required approval by the Sponsor. All doses were administered at the same time of day $( \pm 1 \mathrm{~h}$ ), 7 days apart. "Subjects had follow-up telephone contact on Day 36 ( \pm 1 day) to assess safety. Subjects who discontinued prior to Visit 6 had follow-up telephone contact 5 to 7 days after their last study treatment. EOT, end of treatment

The objective was to assess the bioavailability of GLY administered by the two devices. Oral administration of activated charcoal was added to the treatments to assess drug deposition in the oropharynx and absorption in the gastrointestinal system.

\section{Lung function}

Spirometry was performed at 45 and 15 min pre-dose; and at 15 and $60 \mathrm{~min}$ post-dose during each treatment period in accordance with guidelines of the American Thoracic Society/European Respiratory Society standards 2005 [9]. Subjects receiving IV treatment were not included in these assessments. Recordings were made with a Vitalograph spirometer (Buckingham, UK). Spirometry assessments had a window of $\pm 5 \mathrm{~min}$. Subjects with a decrease in $F E V_{1}$ of $20 \%$ or greater (based on visit pre-dose value compared with screening value) were evaluated by the investigator for continuation in the study.

\section{Charcoal block method}

The charcoal block method can be used to determine the extent of systemic absorption via the lungs versus the gastrointestinal tract [10]. Activated charcoal (Carbomix, Beacon Pharmaceuticals, Tunbridge Wells, UK) was supplied as black granules in plastic bottles containing $81.3 \%$ activated charcoal (50 g in $61.5 \mathrm{~g}$ granules). Prior to use, the activated charcoal was mixed with water to form an oral suspension. A dose of $30 \mathrm{~g}$ was administered as a slurry in $260 \mathrm{~mL}$ water $2 \mathrm{~min}$ prior to inhalation then $5 \mathrm{~g}$ of activated charcoal as a slurry in $35 \mathrm{~mL}$ water post-dose at $2 \mathrm{~min}$, and 1,2 and $3 \mathrm{~h}$. In total, $50 \mathrm{~g}$ of activated charcoal in a total of $400 \mathrm{~mL}$ water slurry was administered to each subject per charcoal arm.

\section{Efficacy and safety assessments}

The efficacy objective of this study compared the effect of GLY delivered by the eFlow CS nebulizer with the DPI device on spirometric measurements. A secondary objective was to assess the safety of GLY inhalation administered by the eFlow CS nebulizer.

\section{Statistical analysis}

Randomized subjects who received at least one dose of the study drug were included in the statistical analysis. All statistical procedures were performed using SAS ${ }^{\circ}$ Version 9.2 or higher (SAS Institute Inc., Cary, NC). Measurements for spirometry, vital signs and PK parameters were analyzed using nominal visits, as applicable.

PK analyses were conducted using all subjects who were randomized, received any study drug and had evaluable PK data. Unusually high concentrations were excluded from the PK analysis as well as the descriptive statistics of concentrations. Individual subjects with AUC extrapolation greater than $20 \%$ were excluded from descriptive statistics for $\mathrm{AUC}_{0-\infty}, \mathrm{F}, \mathrm{CL}, \mathrm{CL} / \mathrm{F}, \mathrm{V}_{\mathrm{z}}$ and $\mathrm{V}_{\mathrm{z}}$ I F. Analysis of PK data was performed using WinNonlin Version 7.0 (Certara, Inc., Princeton, NJ).

A mixed-effect analysis of variance (ANOVA) was performed on the log-transformed $\mathrm{C}_{\max }, \mathrm{AUC}_{0-24}$ and $\mathrm{AUC}_{0-\infty}$, with terms for site, sequence, period and treatment as fixed effects. Subject nested within sequence were treated as a random effect. The results were transformed back to the original scale by exponentiation to provide geometric least-squares (LS) means and ratios, along with $90 \%$ confidence intervals (CIs). No adjustments were made for multiple comparisons. Safety endpoints were analyzed using descriptive statistics.

\section{Results}

\section{Patient characteristics}

A total of 30 subjects underwent randomization at two sites and $26(87 \%)$ completed the study. A total of four patients discontinued: one lost to follow up (due to a family emergency); one requested to be withdrawn as they did not feel stable enough on the replacement inhaler; one could not commit to all overnight stays due to work commitments; and one was not brought in for Visit 2 after recruitment closed. Characteristics of the 
subjects at baseline are described in Table 2. All randomized subjects were included in the PK analysis. No major protocol deviations were reported. No subjects had a COPD exacerbation within 12 months prior to the study. The majority of subjects $(73 \%)$ had moderate COPD and more were current smokers (57\%) than former smokers.

\section{Pharmacokinetics}

GLY plasma concentrations reached peak levels rapidly following single-dose administration (Fig. 3). As expected, peak concentration after the IV infusion was much higher, and time to reach peak plasma concentration faster than those in subjects receiving the inhaled treatments. After $\mathrm{C}_{\max }$ was reached, plasma GLY concentrations rapidly declined. After $12 \mathrm{~h}$, terminal half-life was similar among all treatments.

PK parameters are presented in Table 3. Following the single-dose administration of treatments, the $\mathrm{C}_{\max }$ values were $200 \mathrm{pg} / \mathrm{mL}$ for GLY/DPI (dose-normalized $\mathrm{C}_{\max } 180 \mathrm{pg} / \mathrm{mL}$ ), GLY/eFlow $61 \mathrm{pg} / \mathrm{mL}$ (dose-normalized $98 \mathrm{pg} / \mathrm{mL}$ ), GLY/DPI with charcoal $159 \mathrm{pg} / \mathrm{mL}$ (dose-normalized $143 \mathrm{pg} / \mathrm{mL}$ ), GLY/eFlow with charcoal $58 \mathrm{pg} / \mathrm{mL}$ (dose-normalized $91 \mathrm{pg} / \mathrm{mL}$ ) and IV infusion $5287 \mathrm{pg} / \mathrm{mL}$. Dose-normalized $\mathrm{AUC}_{0-24}$ values for GLY/ DPI were $523 \mathrm{~h} * \mathrm{pg} / \mathrm{mL}$ and for GLY/eFlow were 435 $\mathrm{h}$ "pg/mL, respectively.

Due to variability in the PK parameters, precise quantitative comparisons of PK between dose administration

Table 2 Subject characteristics at baseline

\begin{tabular}{|c|c|c|}
\hline Baseline demographics & Total $(N=30)$ & \\
\hline Age - Mean (SD), years & $60.5(6.6)$ & \\
\hline Age - Range, years & $40-70$ & \\
\hline Female, n (\%) & $6(20.0)$ & \\
\hline Male, n (\%) & $24(80.0)$ & \\
\hline Active smoker, n (\%) & $17(56.7)$ & \\
\hline Former smoker, n (\%) & $13(43.3)$ & \\
\hline $\begin{array}{l}\text { Number of pack-years - Mean } \\
(\mathrm{SD}) \text {, years }\end{array}$ & $42.9(16.40)$ & \\
\hline $\begin{array}{l}\text { Number of pack-years - Range, } \\
\text { years }\end{array}$ & $14-88$ & \\
\hline Parameter & $\begin{array}{l}\text { Pre- } \\
\text { bronchodilator }\end{array}$ & $\begin{array}{l}\text { Post- } \\
\text { bronchodilator }^{\mathrm{a}}\end{array}$ \\
\hline $\mathrm{FEV}_{1}-$ Mean (SD), L & $1.48(0.48)$ & $1.73(0.41)$ \\
\hline $\begin{array}{l}\text { Pre-bronchodilator FVC - Mean } \\
\text { (SD), L }\end{array}$ & $3.27(0.68)$ & $3.72(0.73)$ \\
\hline $\begin{array}{l}\text { Percent predicted FEV } 1 \text { - Mean } \\
\text { (SD), \% }\end{array}$ & $51.4(15.08)$ & $56.8(12.96)$ \\
\hline $\mathrm{FEV}_{1} / \mathrm{FVC}$ - Mean (SD), \% & $49.8(11.12)$ & $51.9(12.16)$ \\
\hline
\end{tabular}

FEV ${ }_{1}$ forced expiratory volume in $1 \mathrm{~s}, F V C$ forced vital capacity, SD standard deviation

${ }^{\mathrm{a}}$ Following inhalation of ipratropium bromide with GLY/eFlow and GLY/DPI could not be performed. However, the dose-normalized PK results were sufficient to support qualitative comparisons between the two devices. Overall, the fraction of inhaled dose of GLY absorbed into plasma via the lung from the two devices was comparable. The total systemic bioavailability of GLY after dose administration from the two devices was also comparable.

GLY/DPI with activated charcoal treatment compared with the same inhaler with no added activated charcoal showed a geometric LS mean ratio $(90 \% \mathrm{CI})$ for $\mathrm{C}_{\max }$ and $\mathrm{AUC}_{0-24}$ of $0.91(0.69,1.19)$ and $0.92(0.67,1.28)$, respectively. The addition of activated charcoal to GLY/ eFlow and GLY/DPI treatments led to an approximate $10 \%$ reduction of $\mathrm{C}_{\max }$ and $\mathrm{AUC}_{0-24}$, indicating that $90 \%$ of systemic exposure was due to pulmonary absorption of both inhaled medications. The effect of the addition of oral activated charcoal on systemic bioavailability of GLY is shown in Fig. 4.

When GLY/eFlow without activated charcoal was compared with GLY/DPI without activated charcoal, the geometric LS mean ratio $(90 \% \mathrm{CI})$ for dose-normalized $\mathrm{C}_{\max }$ and $\mathrm{AUC}_{0-24}$ were $0.58(0.44,0.75)$ and $0.68(0.49$, $0.93)$, respectively. GLY/eFlow with activated charcoal compared with GLY/DPI with activated charcoal gave a geometric LS mean ratio $(90 \% \mathrm{CI})$ for dose-normalized Cmax and AUC0-24 of $0.57(0.44,0.75)$ and 0.65 (0.47, $0.90)$, respectively. Without charcoal the absolute systemic bioavailability of GLY/eFlow was approximately $15 \%$, while GLY/DPI showed systemic bioavailability of approximately $22 \%$, based on dose-normalized $\mathrm{AUC}_{0-24}$. GLY/eFlow with activated charcoal compared with no activated charcoal treatment gave a geometric LS mean ratio $(90 \% \mathrm{CI})$ for $\mathrm{C}_{\max }$ and $\mathrm{AUC}_{0-24}$ of $0.90(0.69,1.17)$ and $0.89(0.65,1.22)$, respectively (Fig. 3$)$. The reduction in systemic exposure of GLY with charcoal coadministration was consistent with the results for GLY/ DPI from a previous study [11].

\section{Lung function}

During treatment, spirometry data were only collected from subjects receiving inhaled medication (Table 2). Baseline mean \pm SD predicted $F E V_{1}$ was $51 \pm 15 \%$ with a $\mathrm{FEV}_{1} / \mathrm{FVC}$ ratio of $50 \pm 11 \%$. Mean baseline prebronchodilator $\mathrm{FEV}_{1}$ was $1.48 \mathrm{~L}$ (SD: 0.48), while mean baseline post-bronchodilator $\mathrm{FEV}_{1}$ was $1.73 \mathrm{~L}$ (SD: 0.41). Spirometric parameters showed a mean and median improvement in all treatments at $15 \mathrm{~min}$ following GLY administration, with further improvement at $60 \mathrm{~min}$. These findings are consistent with previous studies [3, 12].

Although the actual GLY delivered dose was numerically higher with GLY/DPI, than GLY/eFlow, clinically important median and mean changes from baseline in $\mathrm{FEV}_{1}$ were observed with both devices at $15 \mathrm{~min}$ after 


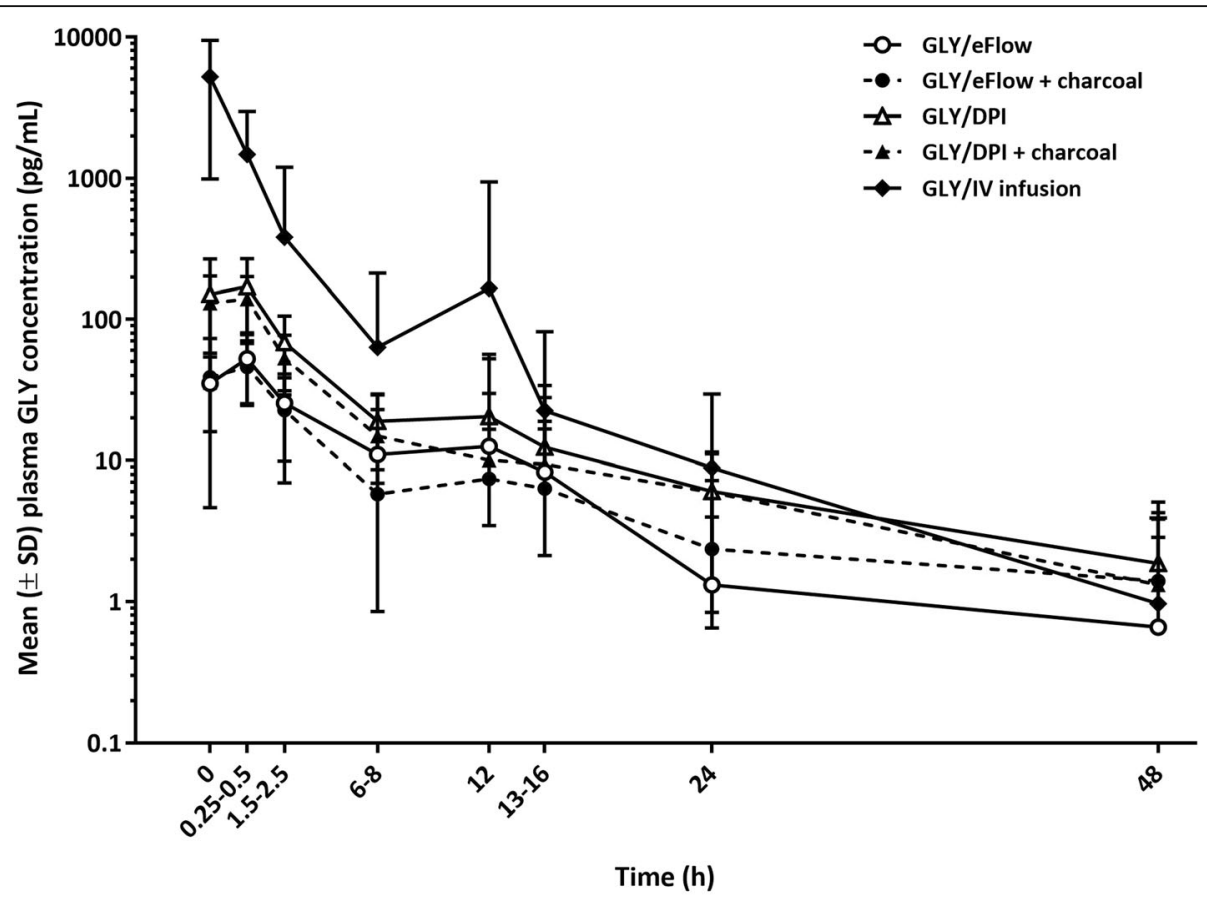

Fig. 3 Mean $( \pm S D)$ glycopyrronium bromide plasma concentration values by treatment (PK population). Note: Pre-dose was 15 min prior to dosing; 0 was immediately at the end of the inhalation or IV infusion. Unusually high concentration values of $77,400 \mathrm{pg} / \mathrm{mL}, 1,520,000 \mathrm{pg} / \mathrm{mL}$, and 1,250,000 pg/mL were excluded from the PK analysis and descriptive statistics for three subjects receiving IV infusion $50 \mu \mathrm{gg}$. Note: Lower SD bars are missing where values are below zero; negative values cannot be displayed on a logarithmic scale. DPI, dry powder inhaler. GLY, glycopyrronium bromide. IV, intravenous. PK, pharmacokinetic. $\mathrm{SD}$, standard deviation

administration, with further improvements at $1 \mathrm{~h}$ postdose (Fig. 5). The mean improvements in $\mathrm{FEV}_{1}$ showed a trend to a higher value with GLY/DPI than with GLY/ eFlow, with and without charcoal (Fig. 5). Direct comparisons of $\mathrm{FEV}_{1}$ by treatment group were not made since the delivered doses of GLY were numerically different $(\mathrm{GLY} / \mathrm{DPI}=55.4 \mu \mathrm{g}$; GLY/eFlow $=31.5 \mu \mathrm{g})$.

There were no differences in the increase in $\mathrm{FEV}_{1}$ or FVC from baseline without charcoal $\left(\triangle \mathrm{FEV}_{1} 15 \mathrm{~min}\right.$ post-dose $0.16 \pm 0.15$ vs $0.095 \pm 0.18 \mathrm{~L}$ and at $1 \mathrm{~h}$ postdose $0.23 \pm 0.16$ vs $0.15 \pm 0.20 \mathrm{~L}$ for GLY/DPI and GLY/ eFlow without charcoal, respectively. $\triangle \mathrm{FVC}$ at $15 \mathrm{~min}$ post-dose was $0.32 \pm 0.37 \mathrm{~L}$ vs $0.21 \pm 0.26 \mathrm{~L}$ and at $1 \mathrm{~h}$ post-dose, $0.44 \pm 0.40 \mathrm{~L}$ vs $0.26 \pm 0.36 \mathrm{~L}$ for GLY/DPI and GLY/eFlow, respectively).

\section{Safety evaluation}

There were no deaths or serious AEs (SAEs) reported during the study. Overall, AEs were reported by 6 (20.7\%) to $11(40.7 \%)$ subjects across treatments, with a slightly higher incidence in the charcoal groups (Table 4) . GLY/DPI had a slightly higher incidence of headache and dry mouth. GLY/DPI produced a higher incidence and more severe AEs of headache compared to GLY/ eFlow (Table 4). Three subjects discontinued due to one or more AEs. Most AEs were assessed by the investigator as unrelated to study medication.

\section{Discussion}

Glycopyrronium bromide is an effective bronchodilator in patients with COPD, and can be administered via different delivery devices. This study evaluated the systemic bioavailability and bronchodilator response of GLY treatment administered using a novel eFlow CS nebulizer or DPI. In subjects with moderate-to-severe COPD, GLY/ DPI delivered numerically higher peak and steady state levels of drug compared with GLY/eFlow. Although GLY/eFlow treatment led to lower systemic levels of drug than GLY/DPI, similar, clinically important bronchodilation was produced. Overall, GLY was well tolerated regardless of delivery method, while a slightly higher number of subjects reported adverse events with GLY/DPI than with GLY/eFlow.

Clinical studies have demonstrated that inhaled GLY $50 \mu \mathrm{g}$ monotherapy improves lung function in COPD subjects, with 24-h sustained bronchodilation [3, 13-15]. GLY/eFlow (25 and $50 \mu \mathrm{g}$ BID) has also demonstrated statistical and clinically important improvements in lung function and health status in subjects with moderate-tovery-severe COPD [16, 17]. GLY inhalation powder can be delivered via a dry powder inhaler (Seebri ${ }^{\circledR}$ Breezhaler $^{\circ}$ 
Table 3 Summary of GLY PK parameters by treatment (PK population)

\begin{tabular}{|c|c|c|c|c|c|}
\hline Parameter statistic & $\begin{array}{l}\text { GLY/eFlow } \\
50 \mu \mathrm{g} \\
(\mathrm{N}=29)\end{array}$ & $\begin{array}{l}\text { GLY/eFlow } \\
50 \mu \mathrm{\mu g}+\text { Charcoal } \\
(\mathrm{N}=29)\end{array}$ & $\begin{array}{l}\text { GLY/DPI } \\
63 \mu \mathrm{g} \\
(N=28)\end{array}$ & $\begin{array}{l}\text { GLY/DPI } \\
63 \mu \mathrm{g}+\text { Charcoal } \\
(N=26)\end{array}$ & $\begin{array}{l}\text { IV Infusion } \\
50 \mu \mathrm{g} \\
(N=27)\end{array}$ \\
\hline \multicolumn{6}{|l|}{ Cmax $(p g / m L)$} \\
\hline N & 29 & 29 & 28 & 26 & 27 \\
\hline Mean (SD) & $61.46(39.42)$ & $57.51(36.32)$ & $199.88(121.51)$ & $158.96(62.89)$ & $5287.15(4131.42)$ \\
\hline $\mathrm{CV} \%$ & 64.14 & 63.16 & 60.8 & 39.57 & 78.14 \\
\hline \multicolumn{6}{|l|}{$\operatorname{tmax}(h)$} \\
\hline $\mathrm{N}$ & 29 & 29 & 28 & 26 & 27 \\
\hline Median & 0.32 & 0.25 & 0.25 & 0.25 & 0.10 \\
\hline \multicolumn{6}{|l|}{$t 1 / 2(h)$} \\
\hline N & 13 & 10 & 20 & 20 & 21 \\
\hline Median & 4.66 & 5.08 & 12.99 & 14.20 & 4.69 \\
\hline \multicolumn{6}{|l|}{ AUC0-24 (h*pg/mL) } \\
\hline N & 29 & 29 & 28 & 26 & 27 \\
\hline Mean (SD) & $273.47(442.44)$ & $208.20(152.78)$ & $581.25(321.56)$ & $467.56(187.48)$ & $3314.09(4220.99)$ \\
\hline $\mathrm{CV} \%$ & 161.787 & 73.378 & 55.323 & 40.098 & 127.365 \\
\hline \multicolumn{6}{|l|}{ AUC0-48 (h* $\mathrm{pg} / \mathrm{mL})$} \\
\hline N & 29 & 29 & 28 & 26 & 27 \\
\hline Mean (SD) & $314.90(567.83)$ & $255.48(223.90)$ & 666.06 (393.78) & 546.85 (249.64) & $3375.13(4296.44)$ \\
\hline $\mathrm{CV} \%$ & 180.32 & 87.64 & 59.12 & 45.65 & 127.30 \\
\hline \multicolumn{6}{|l|}{ 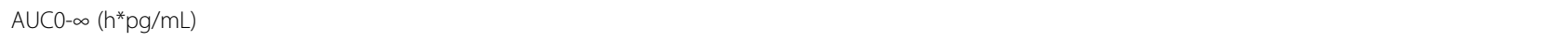 } \\
\hline N & 8 & 6 & 15 & 10 & 21 \\
\hline Mean (SD) & $292.94(237.34)$ & $179.56(75.64)$ & $758.96(510.22)$ & $654.96(347.57)$ & $4009.65(4722.47)$ \\
\hline $\mathrm{CV} \%$ & 81.02 & 42.12 & 67.23 & 53.07 & 117.78 \\
\hline \multicolumn{6}{|l|}{$\mathrm{CL} / \mathrm{F}(\mathrm{L} / \mathrm{h})$} \\
\hline N & 8 & 6 & 15 & 10 & N/A \\
\hline Mean (SD) & $255.12(147.863)$ & 316.99 (117.644) & $127.82(78.670)$ & $131.13(95.031)$ & N/A \\
\hline $\mathrm{CV} \%$ & 57.957 & 37.113 & 61.546 & 72.473 & N/A \\
\hline \multicolumn{6}{|l|}{$\mathrm{V}_{\mathrm{Z}} / \mathrm{F}(\mathrm{L})$} \\
\hline $\mathrm{n}$ & 8 & 6 & 15 & 10 & $\mathrm{~N} / \mathrm{A}$ \\
\hline Mean (SD) & 1316.34 (395.42) & $1690.06(286.28)$ & $1338.96(317.19)$ & 1747.07 (385.31) & N/A \\
\hline CV\% & 30.04 & 16.94 & 23.69 & 22.05 & N/A \\
\hline \multicolumn{6}{|l|}{$C L(L / h)$} \\
\hline $\mathrm{n}$ & $\mathrm{N} / \mathrm{A}$ & $\mathrm{N} / \mathrm{A}$ & $\mathrm{N} / \mathrm{A}$ & $\mathrm{N} / \mathrm{A}$ & 21 \\
\hline Mean (SD) & N/A & N/A & N/A & N/A & $28.13(24.97)$ \\
\hline CV\% & N/A & N/A & N/A & N/A & 88.78 \\
\hline \multicolumn{6}{|l|}{$V_{z}(L)$} \\
\hline $\mathrm{n}$ & N/A & $\mathrm{N} / \mathrm{A}$ & $\mathrm{N} / \mathrm{A}$ & N/A & 21 \\
\hline Mean (SD) & N/A & $\mathrm{N} / \mathrm{A}$ & $\mathrm{N} / \mathrm{A}$ & N/A & 156.02 (111.98) \\
\hline CV\% & N/A & N/A & N/A & N/A & 71.77 \\
\hline \multicolumn{6}{|l|}{$V_{s S}(L)$} \\
\hline$n$ & N/A & N/A & N/A & N/A & 21 \\
\hline Mean (SD) & $\mathrm{N} / \mathrm{A}$ & $\mathrm{N} / \mathrm{A}$ & N/A & $\mathrm{N} / \mathrm{A}$ & $51.02(32.57)$ \\
\hline CV\% & N/A & N/A & N/A & N/A & 66.26 \\
\hline
\end{tabular}

AUC area under the plasma concentration-time curve, $C L$ clearance, $C L / F$ apparent clearance, $C_{\max }$ maximum plasma concentration, $C V$ coefficient of variation, $D P I$ dry powder inhaler, GLY glycopyrronium bromide, N/A not applicable, $S D$ standard deviation, $t_{\max }$ time to peak plasma concentration, $t_{1 / 2}$ terminal half-life, $V_{s s}$ volume of distribution at steady state, $V_{z}$ volume of distribution during the elimination phase, $V_{z} / F$ apparent volume of distribution after extravascular dose administration 


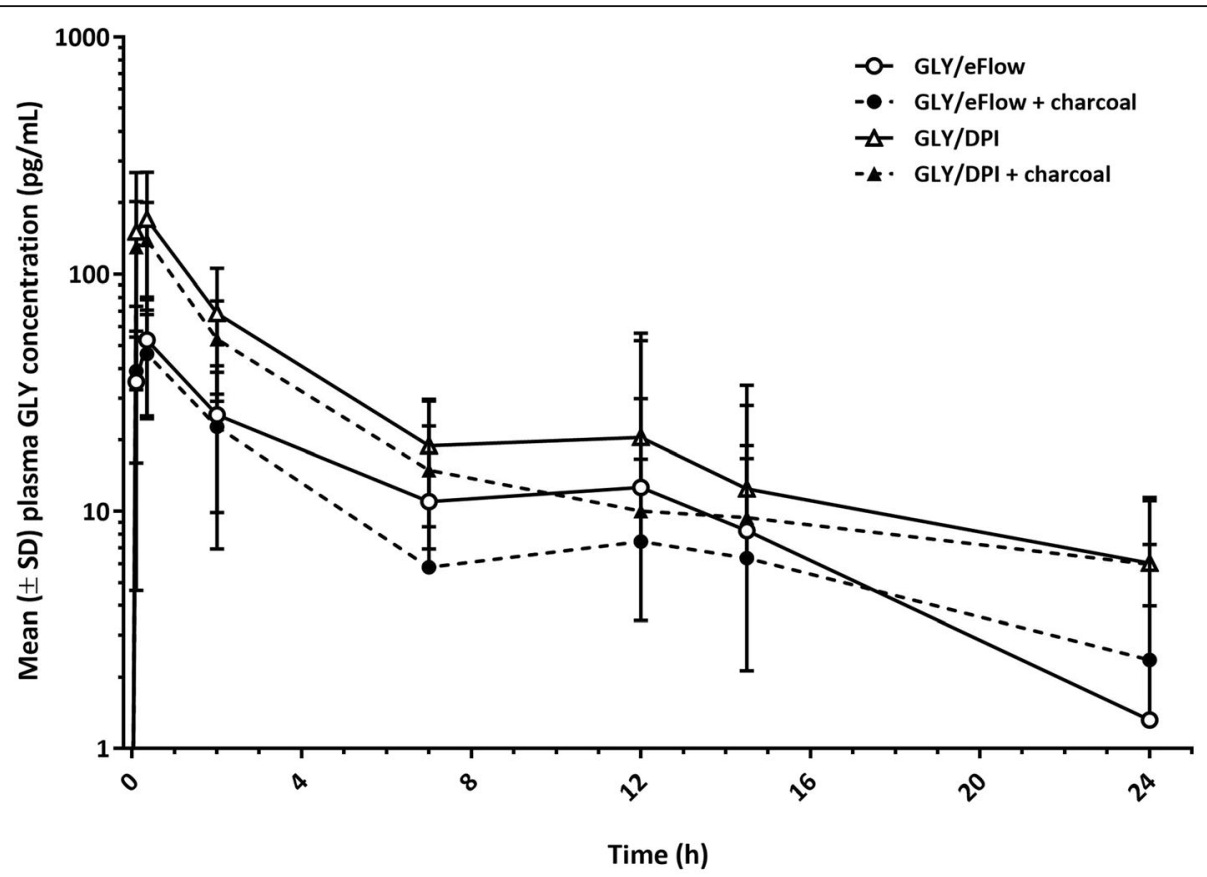

Fig. 4 Comparison of GLY/eFlow versus GLY/DPI fully dose-normalized systemic exposure to glycopyrronium bromide. Note: Lower SD bars are missing where values are below zero; negative values cannot be displayed on a logarithmic scale. DPI, dry powder inhaler. GLY, glycopyrronium bromide. IV, intravenous. SD, standard deviation

[Novartis, EU]/Seebri ${ }^{\bullet}$ Neohaler $^{\oplus}$ [Sunovion, USA]), dual metered dose inhaler (Bevespi Aerosphere ${ }^{\circ}$, AstraZeneca; Ultibro $^{\circ}$ Breezhaler $^{\circ}$ [Novartis, EU]/Utibron ${ }^{\circ}$ Neohaler $^{\circ}$ [Sunovion, USA]) and triple combination inhaler (Trimbow $^{\circ}$, Chiesi; Trelegy ${ }^{\circ}$ Ellipta ${ }^{\circ}$, GlaxoSmithKline).

A nebulized formulation of GLY has been developed for use with the eFlow CS nebulizer and approved by the US Food and Drug Administration for the treatment of COPD patients (Lonhala ${ }^{\circ}$ Magnair $^{\circ}, 25 \mu \mathrm{g}$ BID, Sunovion Pharmaceuticals Inc.) [4]. The eFlow CS device is an electronic nebulizer system, which utilizes a vibrating membrane to aerosolize the drug formulation for administration during normal tidal breathing.

This study evaluated the total systemic exposure and lung bioavailability of GLY/eFlow and GLY/DPI administered with and without activated charcoal in subjects with moderate-to-severe COPD. Plasma concentrations were measured with and without concomitant administration of activated charcoal, which was compared with IV GLY.

The PK observations presented here are consistent with data reported previously, where it was shown that GLY was detectable in the circulation after inhalation ( $t_{\max }$ values of less than $20 \mathrm{~min}$ ), and plasma concentration decreased to less than $10 \%$ at $12 \mathrm{~h}$ post-inhalation $[3,18]$. As expected, the peak concentration with the IV infusion was much higher, and time to reach peak plasma concentration was faster than the other treatments. After $\mathrm{C}_{\max }$ was reached, plasma GLY concentrations rapidly declined. After the 12-h postadministration time point, $t_{1 / 2}$ was similar among all treatments.

Our results are comparable with those of a population PK analysis conducted using GLY concentration-time data from four clinical studies involving 117 patients with moderate-to-severe COPD (Sunovion, data on file). As assessed by the population PK analysis, there was no effect of age, gender, race, weight and COPD severity on the PK of GLY/eFlow. Model-based diagnostics suggested that the exposure to GLY/eFlow increased with dose in a linear manner up to $400 \mu \mathrm{g}$. The mean apparent total systemic clearance (CL/F) for a typical patient was $206 \mathrm{~L} / \mathrm{h}$ (coefficient of variation [CV\%], 28\%).

The peak GLY plasma concentration after dosing was numerically lower in the GLY/eFlow treatment arm compared to the GLY/DPI treatment arm, which is likely due to the numerically lower delivered dose. However, from $2 \mathrm{~h}$ post-dose there was no difference in plasma concentration between the two treatments. The absolute bioavailability of GLY/eFlow is estimated to be approximately $15 \%$, and the absolute bioavailability of GLY/DPI is estimated to be approximately $22 \%$.

AUC measurements give an indication of total systemic exposure via oral and pulmonary routes for compounds that do not have an extensive first pass effect. By administering charcoal $5 \mathrm{~min}$ prior to dosing with 


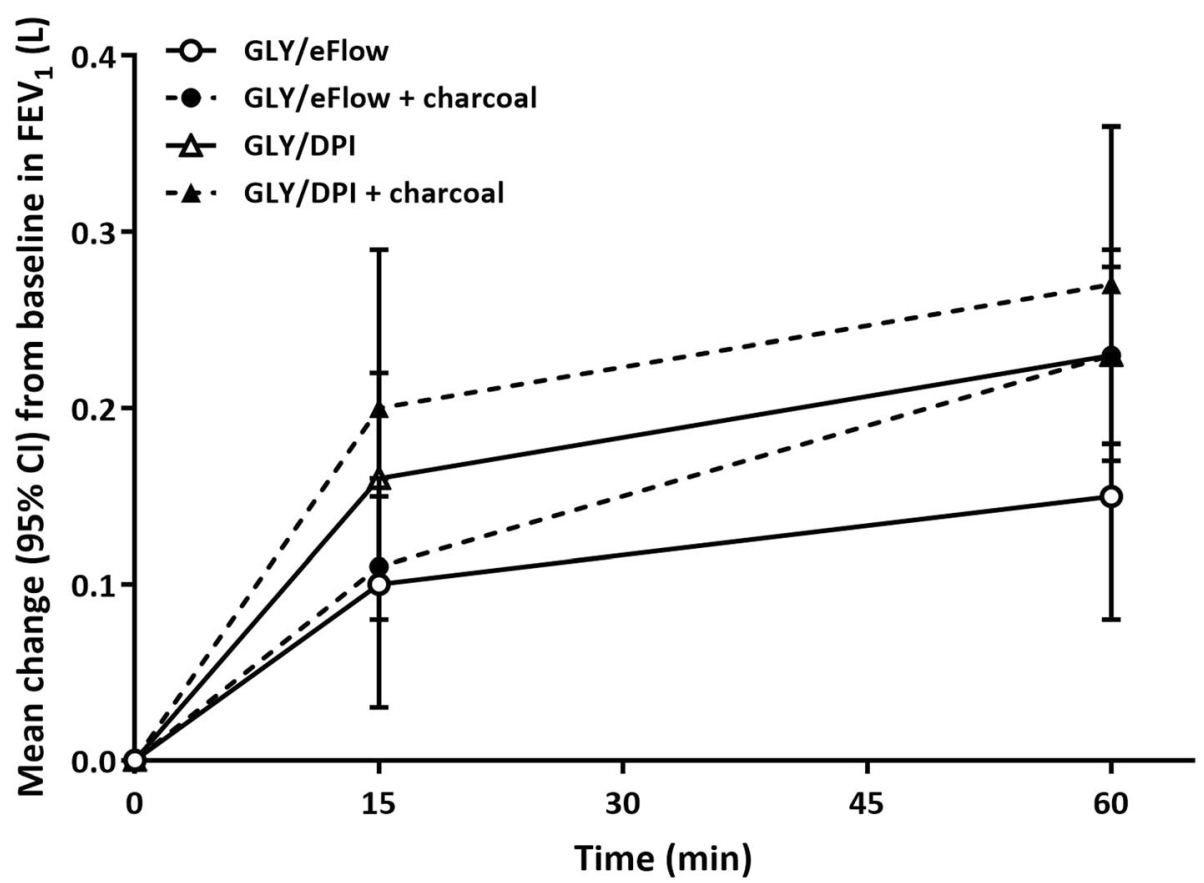

Fig. 5 Summary of mean $\mathrm{FEV}_{1}$ (L) by time point on treatment day. Cl, confidence interval. DPI, dry powder inhaler. FEV ${ }_{1}$, forced expiratory volume in $1 \mathrm{~s} . \mathrm{GLY}$, glycopyrronium bromide

inhaled medication, non-pulmonary absorption is substantially reduced, therefore giving an indication of total pulmonary exposure. This study reports that approximately $90 \%$ of systemic exposure to GLY was from GLY deposited in the airways and only $10 \%$ was from GLY absorption in the oropharynx and gastrointestinal system. This is indicated by the reduction of both $C_{\max }$ and $\mathrm{AUC}_{0-24}$ with charcoal co-administration, as compared with GLY administered without charcoal. A previous study assessing systemic exposure and lung deposition of different delivery methods using the charcoal-block method confirmed that AUC is a suitable measurement of lung bioavailability [19].

GLY/DPI delivered approximately double the $\mathrm{AUC}_{0-24}$ levels of GLY than GLY/eFlow after single-dose administration. It should be emphasized that GLY/DPI delivered a higher absolute dose $(55.4 \mu \mathrm{g})$ than GLY/eFlow $(31.5 \mu \mathrm{g})$. However, the increase in systemic PK values for GLY/DPI may also reflect greater efficiency of drug delivery. The higher peak levels may account for the marginally higher adverse events recorded for GLY/DPI. There was no substantial difference in spirometry measurements between GLY/DPI and GLY/eFlow. GLY/ eFlow produced similar bronchodilation but lower systemic levels of drug with no major absorption through the upper gastrointestinal tract, as demonstrated by the charcoal-block method.

We observed clinically relevant improvements in lung function shortly after drug administration, which further improved for at least $45 \mathrm{~min}$. In general, the median changes in $\mathrm{FEV}_{1}$ from baseline values were numerically higher for both drug formulations without charcoal administration. A direct comparison of $\mathrm{FEV}_{1}$ was not made since the delivered doses of GLY were numerically different (GLY/DPI = $55.4 \mu \mathrm{g}$; GLY/eFlow $=31.5 \mu \mathrm{g}$ ). The median improvement in $\mathrm{FEV}_{1}$ at $1 \mathrm{~h}$ post-dose for GLY/DPI with or without charcoal was $0.220 \mathrm{~L}$, whereas for GLY/eFlow with or without charcoal was $0.220 \mathrm{~L}$ and $0.180 \mathrm{~L}$, respectively. This study showed that both GLY formulations have clinically meaningful benefit in the selected study population [20].

GLY/eFlow was well tolerated. There were no deaths or SAEs. The AE profile in this study was consistent with those reported in larger studies. The incidence and severity of anticholinergic AEs were numerically higher in GLY/DPI compared to GLY/eFlow and higher in both charcoal groups. This $\mathrm{AE}$ profile is likely to correlate with the higher $C_{\max }$ seen in the GLY/DPI group that occurred immediately after drug administration.

It is important to note that subjects in this study were appropriately trained to use the DPI device. In real-life settings, this is unfortunately not the case; several studies have shown that patients, especially the elderly cohorts, commit at least one error when using their devices, mostly associated with coordination and actuation [5, 21-23].

While lung function tests and exercise ability are a reliable aspect of the assessment of treatment for obstructive lung diseases, other factors, such as patient experience and 
Table 4 Adverse events reported by subjects

\begin{tabular}{|c|c|c|c|c|c|}
\hline Adverse events, n (\%) & $\begin{array}{l}\text { GLY/eFlow } \\
50 \mu g \\
(N=29)\end{array}$ & $\begin{array}{l}\text { GLY/eFlow } \\
50 \mu g+\text { Charcoal } \\
(N=29)\end{array}$ & $\begin{array}{l}\text { GLY/DPI } \\
63 \mu \mathrm{g} \\
(N=28)\end{array}$ & $\begin{array}{l}\text { GLY/DPI } \\
63 \mu g+\text { Charcoal } \\
(N=27)\end{array}$ & $\begin{array}{l}\text { IV Infusion } \\
50 \mu \mathrm{g} \\
(N=27)\end{array}$ \\
\hline Any AE & $6(20.7)$ & $9(31.0)$ & $7(25.0)$ & $11(40.7)$ & $7(25.9)$ \\
\hline Ear and labyrinth disorders & $1(3.4)$ & $1(3.4)$ & 0 & 0 & 0 \\
\hline Cerumen impaction & $1(3.4)$ & 0 & 0 & 0 & 0 \\
\hline Ear pain & 0 & $1(3.4)$ & 0 & 0 & 0 \\
\hline Gastrointestinal disorders & $1(3.4)$ & $3(10.3)$ & 0 & $3(11.1)$ & 0 \\
\hline Abdominal discomfort & 0 & 0 & 0 & $1(3.7)$ & 0 \\
\hline Abdominal pain & 0 & $2(6.9)$ & 0 & 0 & 0 \\
\hline Dry mouth & 0 & 0 & 0 & $1(3.7)$ & 0 \\
\hline Nausea & 0 & $1(3.4)$ & 0 & 0 & 0 \\
\hline Toothache & $1(3.4)$ & 0 & 0 & $1(3.7)$ & 0 \\
\hline Vomiting & 0 & $1(3.4)$ & 0 & 0 & 0 \\
\hline $\begin{array}{l}\text { General disorders and administration site } \\
\text { conditions }\end{array}$ & $1(3.4)$ & 0 & $2(7.1)$ & $2(7.4)$ & 0 \\
\hline Catheter site hematoma & 0 & 0 & 0 & $1(3.7)$ & 0 \\
\hline Catheter site pain & 0 & 0 & 1 (3.6) & $1(3.7)$ & 0 \\
\hline Influenza like illness & $1(3.4)$ & 0 & 0 & 0 & 0 \\
\hline Malaise & 0 & 0 & 0 & $1(3.7$ & 0 \\
\hline Vessel puncture site hematoma & 0 & 0 & $1(3.6)$ & 0 & 0 \\
\hline Infections and infestations & 0 & $2(6.9)$ & $1(3.6)$ & 0 & $1(3.7)$ \\
\hline Ear infection & 0 & 0 & $1(3.6)$ & 0 & 0 \\
\hline Gastroenteritis & 0 & $1(3.4)$ & 0 & 0 & 0 \\
\hline Influenza & 0 & 0 & 0 & 0 & $1(3.7)$ \\
\hline Nasopharyngitis & 0 & $1(3.4)$ & 0 & 0 & 0 \\
\hline $\begin{array}{l}\text { Musculoskeletal and connective tissue } \\
\text { disorders }\end{array}$ & $1(3.4)$ & 0 & $2(7.1) 0$ & $1(3.7) 0$ & 0 \\
\hline Back pain & 0 & 0 & $2(7.1)$ & $1(3.7)$ & 0 \\
\hline Musculoskeletal discomfort & $1(3.4)$ & 0 & 0 & 0 & 0 \\
\hline Nervous system disorders & $1(3.4)$ & $4(13.8)$ & $1(3.6)$ & $4(14.8)$ & $4(14.8)$ \\
\hline Headache & $1(3.4)$ & $3(10.3)$ & $1(3.6)$ & $4(14.8)$ & $4(14.8)$ \\
\hline Migraine & 0 & $1(3.4)$ & 0 & 0 & 0 \\
\hline Psychiatric disorders & 0 & 0 & 0 & 0 & $1(3.7)$ \\
\hline Panic attack & 0 & 0 & 0 & 0 & $1(3.7)$ \\
\hline Respiratory, thoracic and mediastinal disorders & $1(3.4)$ & $1(3.4)$ & $2(7.1)$ & $1(3.7)$ & $1(3.7)$ \\
\hline Cough & $1(3.4)$ & $1(3.4)$ & 0 & 0 & 0 \\
\hline Dry throat & 0 & 0 & 1 (3.6) & 0 & $1(3.7)$ \\
\hline Dyspnea & 0 & 0 & 0 & $1(3.7)$ & 0 \\
\hline Oropharyngeal pain & 0 & 0 & $1(3.6)$ & 0 & 0 \\
\hline Skin and subcutaneous tissue disorders & $1(3.4)$ & $1(3.4)$ & 0 & 0 & 0 \\
\hline Ecchymosis & $1(3.4)$ & $1(3.4)$ & 0 & 0 & 0 \\
\hline Vascular disorders & 0 & 0 & 0 & $1(3.7)$ & $1(3.7)$ \\
\hline Hypertension & 0 & 0 & 0 & $1(3.7)$ & 0 \\
\hline Phlebitis & 0 & 0 & 0 & 0 & $1(3.7)$ \\
\hline
\end{tabular}

$A E$ adverse event, $D P I$ dry powder inhaler, GLY glycopyrronium bromide 
quality of life should be taken into consideration when treatment recommendations are made. A relevant aspect of determining the appropriate device for a patient is their preference, which also may be related to a better quality of life due to improved treatment satisfaction. For patients who prefer using nebulizers instead of inhalers [24], the eFlow CS device could be an alternative treatment option.

\section{Conclusion}

The results of this study show that charcoal reduced plasma GLY $\mathrm{AUC}_{0-24}$ by approximately $10 \%$ for both GLY/eFlow and GLY/DPI, suggesting most of the plasma exposure to GLY was via pulmonary absorption, irrespective of inhalation device. The absolute systemic bioavailability of GLY was approximately $15 \%$ with the eFlow CS nebulizer and approximately $22 \%$ with the DPI device. Given the variability observed historically and in this study, these PK values are considered to be similar and do not differ substantially from one another. GLY/eFlow was generally well tolerated. All single doses of inhaled study drug resulted in clinically important improvements in lung function and no PK/pharmacodynamic relationship was identified.

\section{Additional file}

Additional file 1: Sequence of treatments. (DOCX $33 \mathrm{~kb})$

\section{Abbreviations}

AE: Adverse events; AUC: Area under the plasma concentration time curve; BID: Twice daily; Cl: Confidence interval; CL: Clearance; $C_{\text {max: }}$ Maximum observed plasma concentration; COPD: Chronic obstructive pulmonary disease; CS: Closed system; CV\%: Coefficient of variation; DPI: Dry powder inhaler; F: Fraction bioavailable; FEV ${ }_{1}$ : Forced expiratory volume in $1 \mathrm{~s}$; FVC: Forced vital capacity; GLY: Glycopyrronium bromide; GOLD: Global Initiative for Chronic Obstructive Lung Disease; ICS: Inhaled corticosteroid; IV: Intravenous; LAMA: Long-acting muscarinic antagonist; LS: Least squares; PK: Pharmacokinetics; pMDI: Pressurized metered dose inhaler; SAE: Serious adverse event; SD: Standard deviation; $t_{1 / 2}$ : Elimination half-life; $t_{\text {max }}$ : Time to reach maximum plasma concentration; $V_{s s}$ : Volume of distribution at steady state; $V_{z}$ : Volume of distribution

\section{Acknowledgments}

This study was funded by Sunovion Pharmaceuticals Inc. Editorial support was provided by Natalie Beavan, CMPP, of FireKite, an Ashfield company, part of UDG Healthcare plc, and funded by Sunovion Pharmaceuticals Inc.

\section{Authors' contributions}

$\mathrm{BRL}, \mathrm{AO}-\mathrm{G}$. and GG designed the research; BRL, DS, GCN, BH and PJB performed the research; all authors analyzed the data, contributed towards drafting and revising the manuscript, approved the final version for submission, and agreed to be accountable for all aspects of the work.

\section{Funding}

This study was funded by Sunovion Pharmaceuticals, Inc.

\section{Availability of data and materials}

Sunovion Pharmaceuticals Inc. is part of a clinical trial data sharing consortium that facilitates access for qualified researchers to selected anonymized clinical trial data. For up-to-date information on data availability please visit https://www.clinicalstudydatarequest.com/Study-Sponsors.aspx and click on Sunovion.

\section{Ethics approval and consent to participate}

We confirm that we have read the Journal's position on issues involved in ethical publication and affirm that this report is consistent with those guidelines.

\section{Consent for publication}

Not applicable.

\section{Competing interests}

TG, AO-G and GG are employees of Sunovion Pharmaceuticals Inc.

\section{Author details}

${ }^{1}$ Respiratory Clinical Trials Ltd, 20 Queen Anne Street, London W1G 8HU, UK. ${ }^{2}$ Medicines Evaluation Unit, Manchester University NHS Foundations Trust, University of Manchester, Manchester, UK. ${ }^{3}$ Sunovion Pharmaceuticals Inc., Marlborough, MA, USA. ${ }^{4}$ National Heart and Lung Institute, Imperial College London, London, UK.

Received: 11 February 2019 Accepted: 25 June 2019

Published online: 28 June 2019

\section{References}

1. Decramer M, Janssens W, Miravitlles M. Chronic obstructive pulmonary disease. Lancet. 2012;379:1341-51.

2. Haddad EB, Patel H, Keeling JE, Yacoub MH, Barnes PJ, Belvisi MG Pharmacological characterization of the muscarinic receptor antagonist, glycopyrrolate, in human and guinea-pig airways. Br J Pharmacol. 1999;127: 413-20.

3. Leaker BR, Barnes PJ, Jones CR, Tutuncu A, Singh D. Efficacy and safety of nebulized glycopyrrolate for administration using a high efficiency nebulizer in patients with chronic obstructive pulmonary disease. Br J Clin Pharmacol. 2015;79:492-500.

4. Sunovion Pharmaceuticals Inc. LONHALA ${ }^{\oplus}$ MAGNAIR ${ }^{\oplus}$ prescribing information. 2018.

5. Melani AS, Bonavia M, Cilenti V, Cinti C, Lodi M, Martucci P, Serra M, Scichilone N, Sestini P, Aliani M, Neri M, Gruppo Educazionale Associazione Italiana Pneumologi Ospedalieri. Inhaler mishandling remains common in real life and is associated with reduced disease control. Respir Med. 2011; 105:930-8.

6. Pham S, Ferguson GT, Kerwin E, Goodin T, Wheeler A, Bauer A. In vitro characterization of the eFlow closed system nebulizer with glycopyrrolate inhalation solution. J Aerosol Med Pulm Drug Deliv. 2018;31:162-9.

7. Chapman KR, Fogarty CM, Peckitt C, Lassen C, Jadayel D, Dederichs J, Dalvi M, Kramer B. Delivery characteristics and patients' handling of two singledose dry-powder inhalers used in COPD. Int J Chron Obstruct Pulmon Dis. 2011;6:353-63.

8. Novartis Pharmaceuticals UK Ltd. Seebri Breezhaler inhalation powder, hard capsules 44mcg. 2018.

9. Miller MR, Hankinson J, Brusasco V, Burgos F, Casaburi R, Coates A, Crapo R, Enright $P$, van der Grinten $C P$, Gustafsson $P$, Jensen $R$, Johnson DC, Maclntyre N, McKay R, Navajas D, Pedersen OF, Pellegrino R, Viegi G, Wanger J, Force AET. Standardisation of spirometry. Eur Respir J. 2005;26: 319-38.

10. Chrystyn $\mathrm{H}$. Methods to identify drug deposition in the lungs following inhalation. Br J Clin Pharmacol. 2001:51:289-99.

11. Bartels C, Looby M, Sechaud R, Kaiser G. Determination of the pharmacokinetics of glycopyrronium in the lung using a population pharmacokinetic modelling approach. Br J Clin Pharmacol. 2013;76:868-79.

12. Rennard SI, Fogarty C, Ferguson GT, Orevillo CJ, St Rose E, Fischer T, Alameda P, Reisner C. A novel glycopyrrolate metered dose inhaler formulation demonstrates superior bronchodilator efficacy relative to placebo and comparable efficacy and safety to Spiriva $a^{\oplus}$ Handihaler ${ }^{\circledast}$ in patients with COPD. Am J Respir Crit Care Med. 2010;181:A4450.

13. D'Urzo A, Ferguson GT, van Noord JA, Hirata K, Martin C, Horton R, Lu Y, Banerji D, Overend T. Efficacy and safety of once-daily NVA237 in patients with moderate-to-severe COPD: the GLOW1 trial. Respir Res. 2011:12:156

14. Chapman KR, Beeh KM, Beier J, Bateman ED, D'Urzo A, Nutbrown R, Henley $\mathrm{M}$, Chen $\mathrm{H}$, Overend T, D'Andrea P. A blinded evaluation of the efficacy and safety of glycopyrronium, a once-daily long-acting muscarinic antagonist, versus tiotropium, in patients with COPD: the GLOW5 study. BMC Pulm Med. 2014;14:4. 
15. D'Urzo AD, Kerwin EM, Chapman KR, Decramer M, DiGiovanni R, D'Andrea P, Hu H, Goyal P, Altman P. Safety of inhaled glycopyrronium in patients with COPD: a comprehensive analysis of clinical studies and post-marketing data. Int J Chron Obstruct Pulmon Dis. 2015;10:1599-612.

16. Kerwin E, Donohue JF, Goodin T, Tosiello R, Wheeler A, Ferguson GT.

Efficacy and safety of glycopyrrolate/eFlow ${ }^{\oplus}$ CS (nebulized glycopyrrolate) in moderate-to-very-severe COPD: results from the glycopyrrolate for obstructive lung disease via electronic nebulizer (GOLDEN) 3 and 4 randomized controlled trials. Respir Med. 2017;32:238-50.

17. Donohue J, Goodin T, Tosiello R, Wheeler A. Dose selection for glycopyrrolate/eFlow phase III clinical studies: results from GOLDEN (Glycopyrrolate for obstructive lung disease via electronic nebulizer) phase II dose-finding studies. Respir Res. 2017;18:202.

18. Singh D, Leaker B, Tutuncu A. Efficacy and safety of nebulized glycopyrrolate (EP-101) for administration using high efficiency nebulizer in patients with COPD. Eur Respir J. 2011;38:865.

19. Singh D, Collarini S, Poli G, Acerbi D, Amadasi A, Rusca A. Effect of AeroChamber plus on the lung and systemic bioavailability of beclometasone dipropionate/formoterol pMDI. Br J Clin Pharmacol. 2011;72: 932-9.

20. Donohue JF. Minimal clinically important differences in COPD lung function COPD. 2005;2:111-24.

21. Tashkin DP, Klein GL, Colman SS, Zayed H, Schonfeld WH. Comparing COPD treatment: nebulizer, metered dose inhaler, and concomitant therapy. Am J Med. 2007;120:435-41.

22. Lavorini F, Magnan A, Dubus JC, Voshaar T, Corbetta L, Broeders M, Dekhuijzen R, Sanchis J, Viejo JL, Barnes P, Corrigan C, Levy M, Crompton GK. Effect of incorrect use of dry powder inhalers on management of patients with asthma and COPD. Respir Med. 2008;102:593-604.

23. Vanderman AJ, Moss JM, Bailey JC, Melnyk SD, Brown JN. Inhaler misuse in an older adult population. Consult Pharm. 2015;30:92-100.

24. Barta SK, Crawford A, Roberts CM. Survey of patients' views of domiciliary nebuliser treatment for chronic lung disease. Respir Med. 2002;96:375-81.

\section{Publisher's Note}

Springer Nature remains neutral with regard to jurisdictional claims in published maps and institutional affiliations.

Ready to submit your research? Choose BMC and benefit from:

- fast, convenient online submission

- thorough peer review by experienced researchers in your field

- rapid publication on acceptance

- support for research data, including large and complex data types

- gold Open Access which fosters wider collaboration and increased citations

- maximum visibility for your research: over $100 \mathrm{M}$ website views per year

At $\mathrm{BMC}$, research is always in progress.

Learn more biomedcentral.com/submissions 